\title{
ESCRITÓRIO DE PROJETOS INTEGRADOS DE ENGENHARIA: UMA EXPERIÊNCIA DE GESTÃO EM BIM
}

\author{
Luciano Sousa $^{(1)}$, Sabrina Gonçalves ${ }^{(1)}$ Camily Barbosa $^{(1)}$ Antonio Cavalcante ${ }^{(1)}$ \\ (1) Universidade Federal do Ceará, Fortaleza
}

\begin{abstract}
Resumo
No contexto do desenvolvimento da tecnologia BIM, definida por Eastman et al. (2014), como uma tecnologia de modelagem e um conjunto de processos associados para produzir, comunicar e analisar modelos de edifícios, e de um mercado de trabalho cada vez mais competitivo e exigente, os estudantes da Universidade Federal do Ceará (UFC) sentiram a necessidade de aproximar o conhecimento teórico à vivência de mercado, em especial, no tocante ao desenvolvimento de projetos em BIM. Nesse âmbito, surge o Escritório de Projetos Integrados de Engenharia (EPE) com o objetivo de fomentar a filosofia BIM no meio acadêmico, agregada à vivência de gestão e de projetos. Nesse sentido, o EPE possui uma estrutura interna de empresa composta por cinco grandes áreas de gestão, representadas pelas diretorias: marketing, gestão de pessoas e recursos, projetos, qualidade e presidência. Os membros do projeto desenvolvem atividades nos cargos ligados à área de gestão, além de atividades relacionadas à elaboração de projetos em BIM. Assim, o EPE desenvolve a modelagem parametrizada dos blocos da UFC de forma que a universidade possa realizar a gestão das edificações de maneira mais eficiente. No âmbito do ensino, o projeto oferece suporte a disciplinas do curso de engenharia civil, dentre as quais Modelagem da Informação e da Construção (MIC), auxiliando os estudantes com o uso de softwares para concepção de projetos em BIM. Com o intuito de aproximar o mercado de trabalho e a academia e difundir o BIM na universidade, desde sua criação foram realizados diversos eventos, com a presença de nomes de referência em BIM, alcançando cerca de 2000 pessoas diretamente. Assim, é evidente que o Escritório de Projetos Integrados de Engenharia oferece a oportunidade a seus membros de chegarem ainda mais preparados a um mercado cada vez mais exigente
\end{abstract}

\section{Introdução}

No contexto da indústria da construção, começou-se a investir cada vez mais na implementação da filosofia BIM (Building Information Modeling, que em português significa Modelagem da Informação da Construção), que é uma tecnologia de modelagem e um conjunto de processos associados para produzir, comunicar e analisar modelos de edifícios[1]. 
BIM é a simulação de um projeto, que consiste na modelagem 3D dos componentes do mesmo, agregando-se toda a informação requerida ao seu planejamento, à construção ou operação, e ao encerramento do ciclo de vida da edificação[2]. Dessa forma, a modelagem da informação associada ao modelo virtual nas etapas construtivas de uma edificação ou até mesmo de uma obra de infraestrutura auxiliam na análise de viabilidade do empreendimento e dá suporte a tomada de decisões de métodos construtivos, de sistemas de operações, de venda dentre outras. Com efeito, ao conceder o acesso a informações mais assertivas com maior facilidade e rapidez, a metodologia BIM, em seu contexto geral, auxilia na melhoria do controle, na redução de prazos e de custos dos empreendimentos.

Percebe-se a grande relevância que o BIM vem ganhando no Brasil, onde observa-se um cenário da iniciativa privada indo ao encontro da iniciativa pública no tocante ao desenvolvimento de projetos e a execução de obras de construção civil e infraestrutura. No país, tem-se a Estratégia BIM BR[3], fundamentada no decreto $\mathrm{n}^{\circ}$ 9.983, que visa à disseminação nacional da metodologia BIM. Por meio deste decreto, o governo demanda que as empresas que atuam em obras e projetos públicos apliquem a metodologia até o ano de 2021, bem como, que as Instituições de Ensino Superior formem profissionais capazes de atuar com a mesma.

Dessa forma, destaca-se a importância da filosofia BIM ser retratada no meio acadêmico e, especialmente, estar presente na formação dos engenheiros que futuramente estarão atuando no mercado de trabalho. Nesse contexto, foi criado o Escritório de Projetos Integrados de Engenharia (EPE), um projeto de extensão na Universidade Federal do Ceará que tem o objetivo de fomentar essa metodologia no meio acadêmico, com o propósito de ser o elo entre o mercado de trabalho e academia, ao passo que oferece aos seus membros a experiência de ser parte de um escritório de projetos ainda na universidade, permitindo uma vivência de práticas de gestão com uma administração embasada na Teoria Geral da Administração[4], que estuda a administração das organizações e empresas do ponto de vista da interação e da interdependência entre seis variáveis principais: tarefa, estrutura, pessoas, tecnologia, ambiente, competitividade. Oferecer essa aproximação com o mercado de trabalho aliada ao desenvolvimento de práticas BIM para os estudantes ainda na graduação é a chave para atender a demanda de um mercado de trabalho cada vez mais exigente.

\section{Metodologia}

\subsection{Origem do Escritório de Projetos Integrados de Engenharia}

Em 2015, no Centro de Tecnologia da Universidade Federal do Ceará, surgiu um grupo de estudos de BIM por iniciativa de alunos e professores a partir da necessidade que os mesmos sentiam de desenvolver o conhecimento de BIM, que emergia no mercado, mas era insuficiente na graduação. Inicialmente, foi montado um cronograma dos assuntos que seriam abordados no decorrer do ano e cada membro do grupo ficava responsável por aprender determinado assunto e repassar aos demais, seguindo os moldes da aprendizagem cooperativa. Os encontros aconteciam semanalmente no Laboratório de Modelagem da Informação - LMI da universidade e contemplavam, além de conceitos da filosofia, conceitos relevantes de construção enxuta, de projetos e, ainda, treinamento da ferramenta Autodesk Revit, que permite construir virtualmente edificações, dando informações necessárias para tomada de decisões. Com o passar do tempo, o grupo de estudos foi formalizado como projeto de extensão em 2017, quando começou a ganhar a forma em que é estruturado atualmente. 


\subsection{Gestão interna do projeto}

A essência do EPE consiste em vivenciar um escritório de projetos dentro do ambiente universitário, portanto ele abrange as etapas do planejamento que uma organização traz consigo em termos de abordagens e estratégias, embasando-se na concepção de Chiavenato[4] de que os antigos controles externos das organizações (regras, regulamentos, procedimentos, horário de trabalho etc.) estão sendo substituídos por conceitos como valores organizacionais, missão da organização, foco no cliente e que permitem orientar o comportamento das pessoas.

Semestralmente é realizado um planejamento estratégico com todos os membros do projeto onde são debatidas e definidas a missão e a visão do projeto, de modo a orientar as atividades que serão realizadas naquele período. Atualmente, a missão do escritório é fomentar a filosofia BIM, contribuindo com a comunidade tecnológica e proporcionar uma vivência de gestão e projetos aos estudantes e sua visão é ser unidade de referência no Nordeste no desenvolvimento e na aplicação da metodologia BIM até 2021. Os valores da organização são excelência acadêmica, melhoria contínua, proatividade, comprometimento, empatia, integridade e sinergia e orientam as ações e as decisões dos membros.

No âmbito da gestão interna, o escritório é dividido em cinco diretorias, que abordam os principais pilares para uma gestão eficiente, permitindo aos membros vivenciarem experiências em diferentes áreas de gestão. As diretorias estão elencadas abaixo:

- Qualidade: Encarregada de analisar, mapear e melhorar os processos internos do EPE, de forma que as atividades sejam executadas de forma eficiente. Além disso, é responsável por elaborar o planejamento estratégico no qual são traçados objetivos e metas e por fazer o acompanhamento em cada diretoria garantindo a realização destes por meio de indicadores e auxiliando, assim, os diretores no cumprimento do planejamento e crescimento da organização.

- Marketing: Responsável pela identidade visual e imagem do EPE, é a diretoria que organiza eventos, aproximando a metodologia BIM da comunidade acadêmica, sendo então o principal portal de comunicação do EPE com o público externo.

- Gestão de Pessoas e Recursos (GPR): A fim de maximizar o potencial dos comportamentos humanos, a GPR é a diretoria encarregada de acompanhar o desempenho dos membros e de promover a capacitação dos mesmos. É ela também quem capta pessoas e realiza os desligamentos, além arquivar e organizar os documentos internos. Também realiza a gestão da sede, dos patrimônios físicos e de recursos financeiros, analisando a viabilidade financeira de projetos e eventos.

- Presidência: É a diretoria responsável pela gestão da produção científica da organização. Ademais, é a imagem do EPE ao público externo, a ponte entre os parceiros externos e a organização, sendo responsável também pela sua prospecção, beneficiando a organização de acordo com seus interesses.

- Projetos: Responsável por ser o canal de comunicação do cliente com o EPE, desde a captação, negociação e fechamento do contrato, até a gestão e comunicação com os clientes durante o andamento do projeto. Deve, portanto, gerir os projetos de forma que os prazos sejam cumpridos e o produto seja entregue com êxito. Além disso, é responsável por criar/atualizar o portfólio e listagem de serviços oferecidos pelo EPE, bibliotecas internas de arquivos relacionados a projetos, manuais de processos construtivos, dando assistência aos projetistas sempre que necessário. 
A fim de gerir melhor o conhecimento desenvolvido na organização, foi montada uma estrutura por meio da qual, além dos membros efetivos, o projeto conta com um conselho de estratégias formado por professores, profissionais do mercado e ex-membros selecionados, que, quando solicitados, prestam auxílio ao EPE.

Os membros do projeto têm se preparado para, a longo prazo, prestar serviços à comunidade, sob a orientação do conselho consultivo. Dessa forma, tem-se traçado estratégias para a abertura do projeto ao mercado, como definição do público alvo e prospecção de clientes, além da revisão da organização interna da organização, em especial no que diz respeito a gestão do fluxo de caixa, que seria feita pela diretoria de Gestão de Pessoas e Recursos, e seria investido totalmente nas atividades realizadas e em capacitações internas, uma vez que o projeto é totalmente voluntário.

\section{Resultados}

O Escritório de Projetos Integrados de Engenharia - EPE, executa diversas atividades as quais são planejadas por meio da metodologia S.M.A.R.T., referente às palavras em inglês Specific, Measurable, Attainable, Realistic, Timely que em português significam específico, mensurável, atingível, realista e com prazo estabelecido, a fim de atingir seus objetivos, dos quais temos:

- Qualificar os membros em conhecimento em BIM e atividades de Gestão.

- Desenvolver novas aplicações e automatizações na metodologia BIM.

- Estimular e auxiliar o uso da metodologia BIM no meio acadêmico.

- Prestar serviços à comunidade, aplicando os conhecimentos adquiridos e desenvolvidos na universidade.

\subsection{Práticas em BIM}

A fim de atingir seus objetivos o EPE vem se desenvolvendo no que tange a aplicação da metodologia BIM. Até o momento foram modelados 23 projetos, dentre eles, as seguintes disciplinas: nove de Arquitetura, um de Estrutura, quatro de Instalações Elétricas, oito de Instalações Hidrossanitárias e um de Pavimentação. Dentre os projetos desenvolvidos, foram inseridas informações necessárias para auxiliar no uso de manutenção e operação de alguns Blocos Didáticos do Centro de Tecnologia da Universidade Federal do Ceará (Figuras 01 a 05). Dentre as informações temos, descrição de materiais, custo e dimensões. Em dois blocos modelados, tem-se informações no tocante a operação e manutenção, como agendamento preventivo de manutenção de aparelhos de ar-condicionado, extintores, instalações elétricas e elevadores. Para a elaboração da estimativa de custo, utilizou-se como referência as tabelas da SINAPI-Sistema Nacional de Preços e Índices para a Construção Civil e da SEINFRASecretaria Estadual de Infraestrutura, mais utilizadas na região, sobretudo no tocante a obras públicas. 


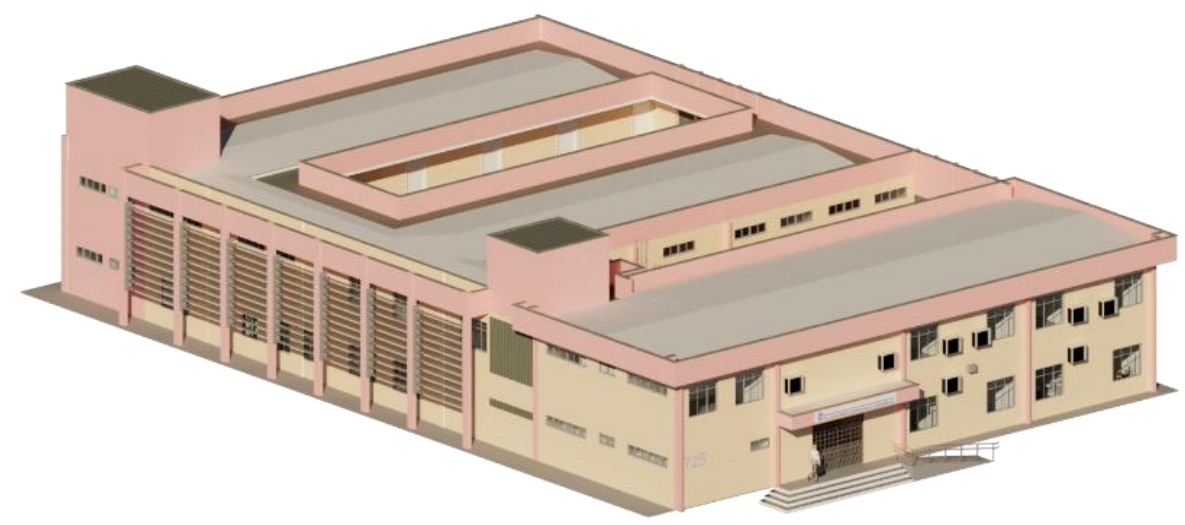

Figura 1: Construção virtual Bloco 725 do Centro de Tecnologia da UFC.

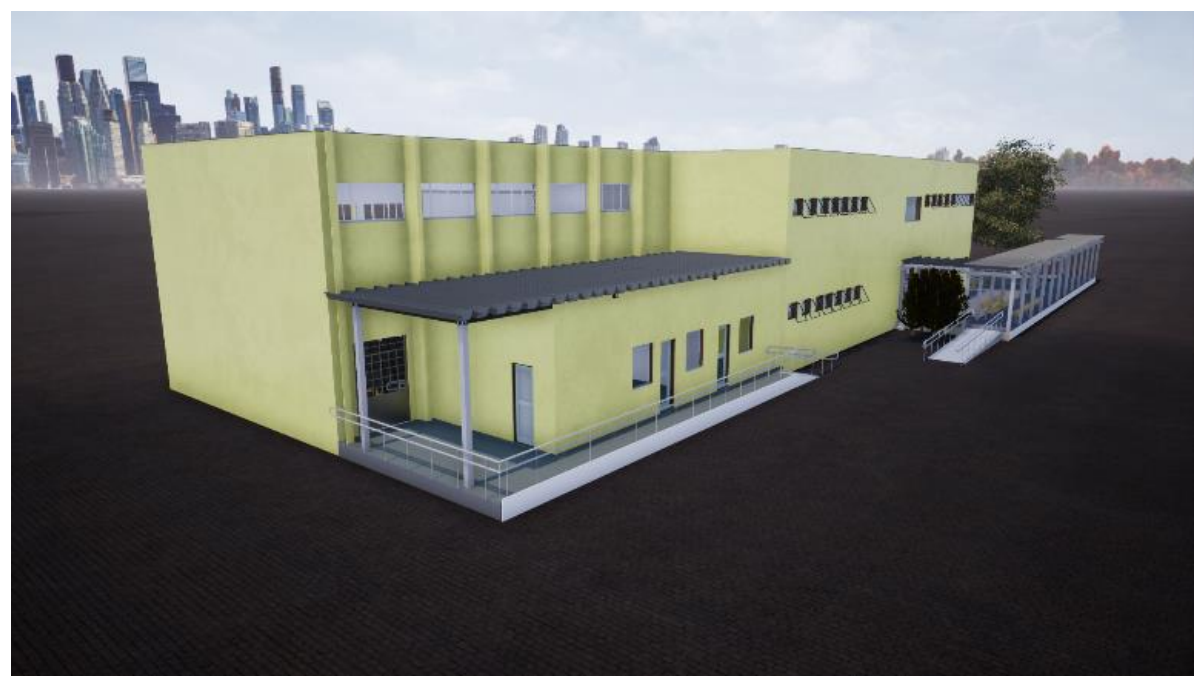

Figura 2: Construção virtual Bloco 708 do Centro de Tecnologia da UFC.

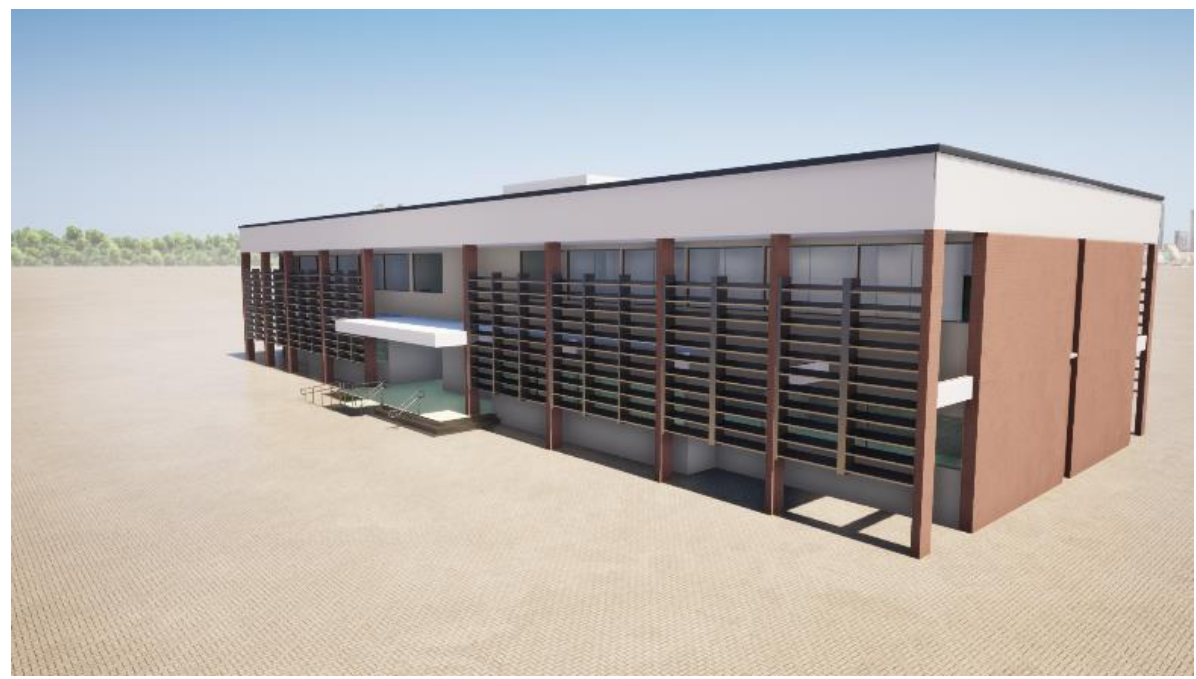

Figura 3: Construção virtual Bloco 710 do Centro de Tecnologia da UFC. 


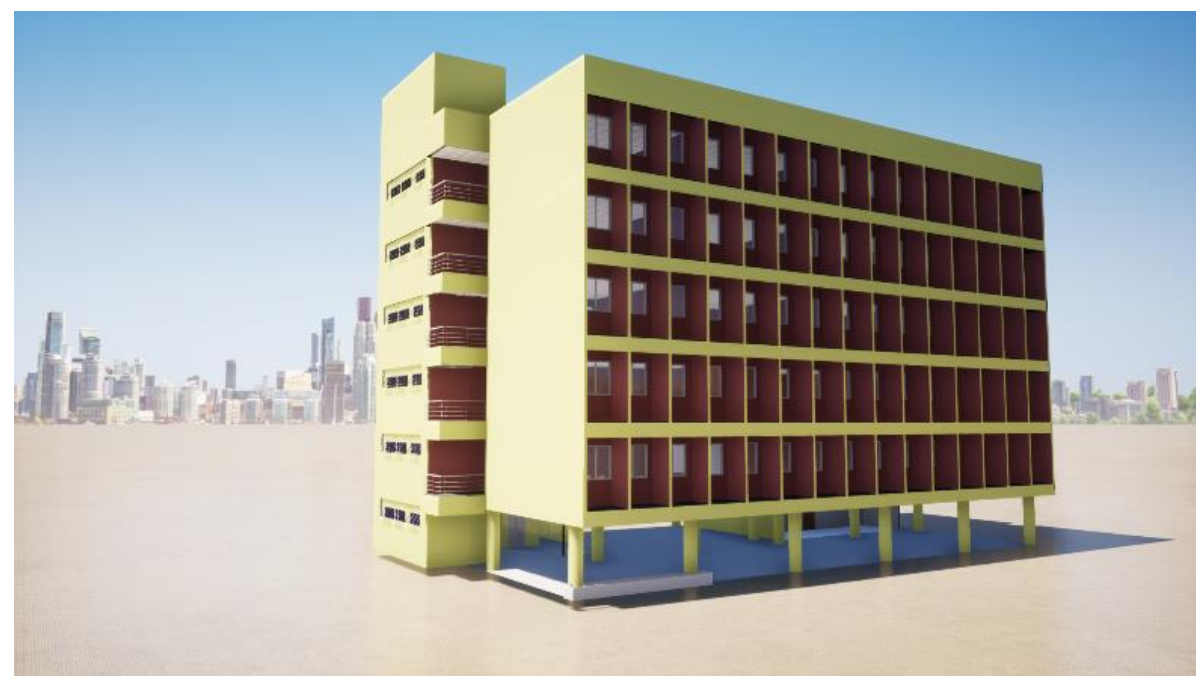

Figura 4: Construção virtual Bloco 707 do Centro de Tecnologia da UFC.

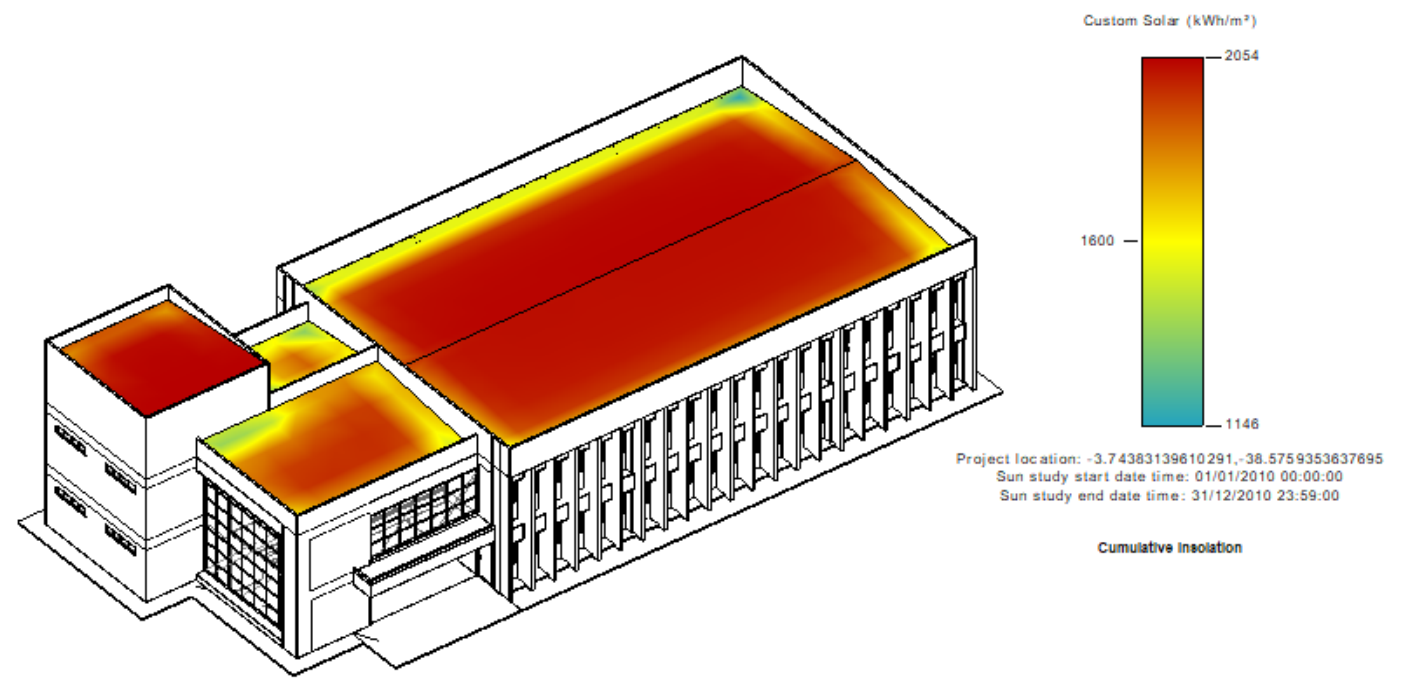

Figura 5: Simulação energética do bloco 727 do Centro de Tecnologia da UFC.

\subsection{Eventos}

Com o fito de disseminar a filosofia BIM na comunidade tecnológica, foi possível realizar uma série de eventos ultrapassando os limites da universidade, trazendo profissionais renomados, tanto do setor público, como o Exército Brasileiro, pioneiro no uso de BIM nesse setor, como da iniciativa privada, desde profissionais locais como EXP Brasil, VMB Engenharia e CERTARE, a profissionais de empresas nacionais, como ALTO QI, e até profissionais de empresas internacionais, como Bentley Systems e Graphisoft. 


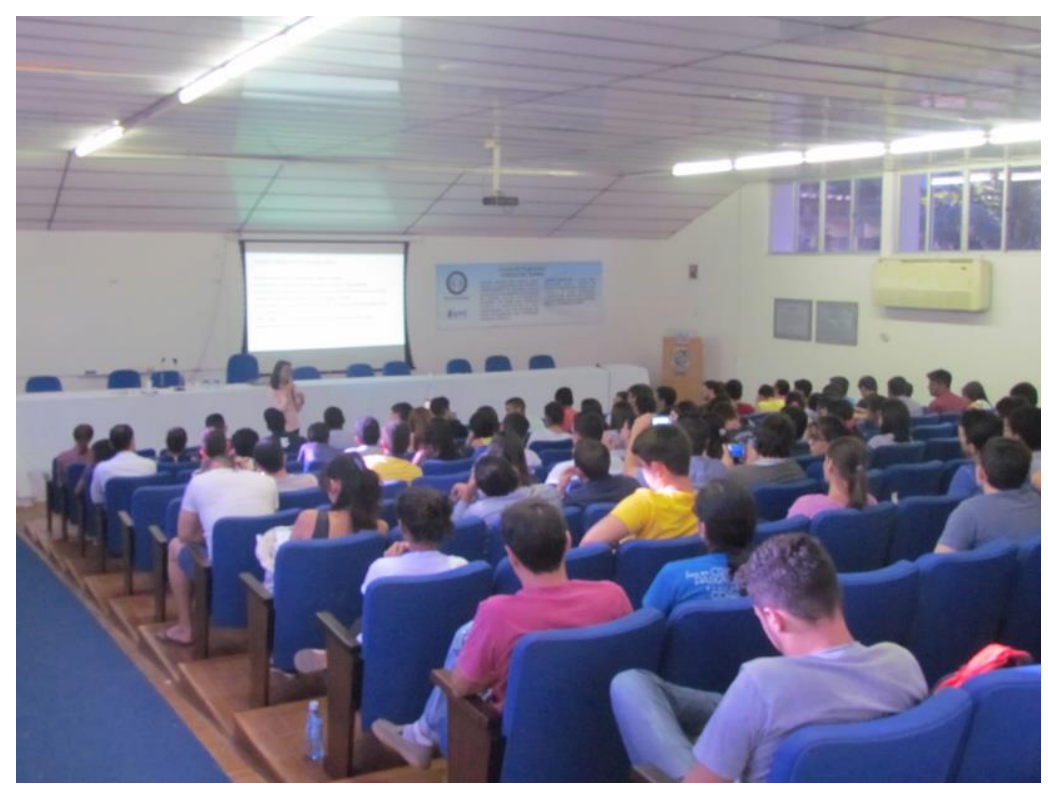

Figura 6: Workshop de BIM realizado no Centro de Tecnologia da UFC.

Dentre esses eventos, ressalta-se o Workshop de BIM (Figura 06), evento realizado pelo projeto que conta com palestras, minicursos e oficinas, sendo uma ponte entre mercado e academia, promovendo debates relevantes para profissionais e estudantes das áreas de engenharias e arquiteturas. Ao todo foram realizados 15 eventos, sendo 3 workshops, 2 palestras, 5 minicursos e 5 lives que contabilizam um impacto direto de 2192 pessoas, mostrando a relevância dessas ações para o meio tecnológico (Tabela 01).

Tabela 1: Quantidade de pessoas impactadas nos eventos. Fonte: autoral

\begin{tabular}{lc}
\hline Evento & Quantidade de pessoas impactadas \\
\hline $1^{\circ}$ Workshop de BIM & 362 \\
$2^{\circ}$ Workshop de BIM & 373 \\
$3^{\circ}$ Workshop de BIM & 326 \\
4 Minicursos de Revit & 100 \\
Minicurso de Autocad & 26 \\
2 Palestras & 247 \\
5 lives & 758 \\
\hline
\end{tabular}

\subsection{Pesquisa}

Quanto ao desenvolvimento interno de produção científica, desenvolve-se, a partir dos projetos elaborados, diferentes metodologias de aplicação do BIM. Essas aplicações buscam envolver gestão de operação e manutenção de edificações, automatização de processos, inovações de 
metodologias de projeto e infraestrutura. Além disso, também são desenvolvidas pesquisas relacionadas à experiência didática e ensino de BIM buscando aprimorar o conhecimento acerca da filosofia além de prestar auxílio à universidade com a inclusão do BIM em suas disciplinas. Dessa forma, procura-se desenvolver metodologias mais automatizadas e eficientes de se realizar a gestão de instalações dos blocos da Universidade, além de análises de eficiência energética, estudo solar e análise térmica que auxiliem ao setor administrativo da universidade na tomada de decisão.

Quanto a inovações de metodologias de projetos, o EPE possui uma metodologia própria de desenvolvimento interno de produtos, registrada nos manuais de construção virtual, inicialmente focando na iniciação a ferramenta de modelagem, padrões utilizados na organização, templates, e métodos de modelagem. Partindo para o passo seguinte que é o foco em dimensionamentos projetuais, orçamento de obras em automatizações com programação visual, e, ainda, a modelagem parametrizada dos blocos didáticos existentes no Centro de Tecnologia, inserindo diversas informações pertinentes com a finalidade de auxiliar os gestores da UFC nas rotinas de operação e manutenção destas edificações.

Dentre os manuais temos o de modelagem arquitetônica, no qual consta o passo a passo de como realizar o projeto considerando o método construtivo adotado, desde a inserção do template padrão utilizado no software, tipos de informações que devem ser inseridos até a completa modelagem do projeto, documentação, retirada de quantitativos e elaboração do orçamento. As mesmas informações são consideradas nos manuais de projetos de hidrossanitário e elétrico, sendo neste caso inseridos ainda o passo a passo de como realizar o dimensionamento do mesmo.Para cada projeto há ainda um checklist dos itens que cada etapa deve conter e um fluxograma a ser seguido. Dessa forma, o processo de modelagem é mapeado e por meio da análise de indicadores como o de produtividade por etapa do projeto desenvolvido e tipos de erros cometidos são buscados soluções e melhorias a fim de que se tenha processos mais eficientes.

\subsection{Ensino}

Sendo o ensino, um dos pilares da organização, e visando estimular a auxiliar o uso da metodologia BIM na universidade, o EPE auxilia no ensino de ferramentas de modelagem BIM em diversas disciplinas do curso. Dentre elas, a disciplina de Modelagem da Informação e da Construção - MIC, sob o código TL0013, ofertada pelo Departamento de Integração Acadêmica e Tecnológica, primeira disciplina de BIM da Universidade Federal do Ceará que trata de da metodologia BIM em todo o ciclo de vida de edificações, bem como a disciplina de Desenho para Engenharia, abordada logo no primeiro ano do curso e a disciplina de Gerenciamento na Construção Civil.

Na disciplina de Desenho para Engenharia os discentes têm o primeiro contato com ferramentas de desenho, atualmente previsto na grade do curso apenas desenho manual e ferramentas CAD, e para complementar a formação dos alunos, o EPE fornece suporte no que tange a introdução da metodologia BIM, bem como, o auxílio no uso da ferramenta Autodesk Revit, para que os alunos consigam desenvolver um projeto passado pelo professor. O suporte supracitado ocorre da seguinte maneira: os membros do EPE fazem uma apresentação sobre a ferramenta, funções iniciais que são necessária para o desenvolvimento do trabalho proposto pelo professor, ficam disponíveis em horários previamente agendados tirando dúvidas, e ainda, elaboram vídeos auxiliares para o melhor entendimento dos discentes.

Já na disciplina de Gerenciamento na Construção Civil, na qual é abordado a retirada de 
quantitativos e orçamentação, bem como o planejamento de uma edificação por meio de métodos tradicionais utilizando-se de ferramentas CAD, o EPE fornece o suporte aos discentes ensinando-lhes como realizar a modelagem da edificação utilizando-se da ferramenta Autodesk Revit e inserir as informações necessárias a fim de se gerar o quantitativo de forma automatizada. Dessa forma, os membros do projeto dão os conceitos iniciais de BIM e as possibilidades que a metodologia oferece, ensinam as funções básicas do software e reservam um horário para que os alunos possam tirar suas dúvidas.

Quanto a disciplina de MIC que aborda todo o ciclo de vida de uma edificação, o EPE fornece um suporte relacionado a ferramentas BIM, ensinando aos alunos tanto a modelagem 3D quanto a inclusão de informações para retirada de quantitativos a fim de se realizar a orçamentação (5D), por meio do software Autodesk Revit, e ainda como elaborar o planejamento (4D) utilizando-se da ferramenta Autodesk Navisworks. Além disso, com o fito de promover a troca de experiências entre os profissionais de mercado, alunos e professores, o EPE convida profissionais da área para demonstrar como é aplicado no mercado de trabalho os conteúdos ensinados na disciplina.

\section{Considerações Finais}

Diante do exposto, o Escritório de Projetos Integrados de Engenharia oferece a oportunidade a seus membros de chegarem ainda mais preparados a um mercado cada vez mais exigente, despertando o espírito empreendedor e proporcionando uma vivência de escritório de projetos, além de desenvolver habilidades interpessoais, de gestão e técnicas, que são importantes para a vivência profissional. No tocante ao ensino, o EPE tem o compromisso de auxiliar os discentes no que tange ao conhecimento da filosofia BIM, colaborando com a disseminação dessa metodologia no meio acadêmico. Ademais, o auxílio fornecido a algumas disciplinas dos cursos de engenharia do CT é essencial para promover a troca de experiências entre alunos, professores e profissionais do mercado que, por meio do projeto, vem a universidade mostrar aos discentes como os conhecimentos adquiridos em sala de aula são aplicados no mercado de trabalho. Os eventos organizados pelo projeto têm mostrado êxito em aproximar o mercado da academia, impactando cada vez mais pessoas. Além disso, o suporte dado ao setor de infraestrutura da universidade configura uma oportunidade de vivenciar a experiência em projetos para os membros, bem como beneficia diretamente a instituição. Com efeito, como um dos grandes valores do EPE, a melhoria contínua norteia algumas ações, dentre elas, a evolução dos projetistas, tanto em ferramentas computacionais de modelagem parametrizada, como também em termos conceituais de BIM, tendendo a subir mais um degrau, o da automatização de processos projetuais.

\section{Referências}

[1] EASTMAN,Charles et al. Manual BIM: Um guia de modelagem da informação da construção para arquitetos, engenheiros, gerentes, construtores e incorporadores. 2a edição. Porto Alegre : Bookman, 2014

[2] KYMMELL, Willem. Building Information Modeling - Planning and Managing Construction Projects with 4D CDA and Simulations. Ebook. McGraw-Hill, 2008 
[3] BRASIL. Mdic. Comitê Estratégico de Bim (Ed.). ESTRATÉGIA BIM BR: Estratégia Nacional de Disseminação do Building Information Modelling - BIM. 2018. Ministério da Indústria, Comércio Exterior e Serviços. Disponível em: <http://www.mdic.gov.br/images/REPOSITORIO/sdci/CGMO/Livreto_Estratgia_BIM_ BR-6.pdf>. Acesso em: 04 fev. 2020.

[4] CHIAVENATO, Idalberto. Introdução à teroria geral da administração: Uma visão abrangente da moderna administração das organizações. 7a edição. Rio de Janeiro: Elsevier, 2003. 